\title{
The ethicolegal framework relevant to human faecal microbiota transplants in South Africa: Part 2. Human stool as tissue?
}

M Labuschaigne, ${ }^{1}$ BA Hons, MA, DLitt, LLB, LLD; M Slabbert, ${ }^{1}$ BA Hons, HED, BProc, LLB, LLD; $\mathbf{S}$ Budree, ${ }^{2}$ MB ChB, DCH, FC Paed (SA), Cert Gastroenterology (SA) Paed; E Hoosien, ${ }^{3}$ MB ChB, MMed Path (Med Microbiol), DTM\&H; A Brink, ${ }^{4}$ MB ChB, MMed (Clin Microbiol); M Blockman, ${ }^{5}$ BPharm, MB ChB, PG Dip Int Res Ethics, MMed (Clin Pharmacol)

${ }^{1}$ Department of Jurisprudence, School of Law, University of South Africa

${ }^{2}$ Department of Paediatrics, Faculty of Health Sciences, University of Cape Town, South Africa; and OpenBiome, Cambridge, Mass., USA

${ }^{3}$ Clinical Microbiology Department, Ampath Laboratories, Centurion, South Africa

${ }^{4}$ Division of Medical Microbiology, Department of Pathology, Faculty of Health Sciences, University of Cape Town, South Africa; and National Health Laboratory Service, Cape Town, South Africa

${ }^{5}$ Division of Clinical Pharmacology, Department of Medicine, Faculty of Health Sciences, University of Cape Town, South Africa

Corresponding author: M Labuschaigne (slabbmn@unisa.ac.za)

Faecal microbiota transplantation (FMT) has been shown to be an effective treatment for recurrent Clostridioides difficile infection. The purpose of this article, the second of a series of three articles, is to explore the legal framework governing human FMT in South Africa (SA). FMT involves different modes of administration that require different regulatory considerations. The focus of this article is to explore the legal classification of human stool as tissue in terms of the National Health Act 61 of 2003, as well as the regulation of human stool banks as tissue banks. The article concludes with specific recommendations aimed at improving the current regulatory vacuum relating to the regulation of FMT in SA.

S Afr Med J 2020;110(8):816-818. https://doi.org/10.7196/SAMJ.2020.v110i8.15069

Faecal microbiota transplantation (FMT) has been shown to be an effective treatment for Clostridioides difficile infection (CDI) and has recently been incorporated into treatment guidelines for recurrent CDI in the USA and Europe. In South Africa (SA), a limited number of patients have been treated for recurrent CDI. FMT involves the introduction of microbiota from a healthy donor to a patient by colonoscopy, enema or a nasogastric tube with the aim of correcting or repairing a perturbed or dysbiotic microbial community. ${ }^{[1]}$ Alternatively, patients may take capsules containing frozen donor bacteria orally. Capsular delivery of FMT was shown to be $96 \%$ effective in treating CDI in one study, with similar efficacy rates to colonoscopic delivery, provided an adequate dose is administered via the capsular administration. ${ }^{[2]}$ FMT capsules may vary by manufacturer; however, they usually have no scent or taste. Some capsules contain a donor-derived faecal slurry, while others comprise lyophilised bacteria. ${ }^{[3,4]}$ Typically, the microbiota is encapsulated within an enteric-coated capsule to enable post-pyloric delivery.

Capsules have some advantages over colonoscopy in that they are non-invasive, without any of the risks associated with procedural sedation, and can be administered in a doctor's office, with the patient required to take between 10 and 40 capsules within 1 hour. ${ }^{[2,45]}$ Delivery of an FMT, whether using a faecal slurry via the colonoscope or nasoduodenal tube or through the use of capsules, points to two different regulatory frameworks: the transplant of human biological material on the one hand, and the regulation of medicines on the other. The legislative framework for the transplantation of human stool as tissue will be the focus of this article.

Although FMT is not new, it has recently gained more attention as a novel and effective treatment for recurrent CDI. In addition, FMT is currently being investigated in the treatment of other microbiomemediated diseases, ranging from inflammatory bowel disease to metabolic diseases, obesity, malnutrition and autism spectrum disorders. $^{[1]}$ In 2015, the South African Gastroenterology Society published a limited guideline on faecal microbiota transplants. The field has evolved significantly since these initial guidelines were published. At present, the regulatory framework surrounding FMT in SA remains unclear.

The purpose of this article is to explore the regulatory framework that applies to the regulation of human stool for the purpose of FMT. Exploring the legal framework governing human stool would require an analysis of human stool and its classification as 'tissue' in terms of the National Health Act 61 of 2003 (NHA).

\section{Human stool as 'tissue' in terms of the NHA}

Chapter 8 of the NHA governs the control of the use of human blood, blood products, tissue and gametes. Tissue is defined in section 1 as 'human tissue, and includes flesh, bone, a gland, an organ, skin, bone marrow or body fluid, but excludes blood or a gamete. Human stool is not included but neither is it excluded, and for the purposes of this article we assume that stool is tissue. Tissue may only be removed from a living person with the informed consent of the donor, obtained in the prescribed manner and in accordance with prescribed conditions (section 55).

The Act stipulates in section 56 that the removed tissue may only be used for such 'medical or dental purposes as may be prescribed', but prohibits, among other things, the removal of tissue from a person who is mentally ill in terms of the Mental Health Care Act 17 of 2002, as well as from a minor, if such tissue is not naturally 
replaceable. Human stool is naturally replaceable and therefore minors should be able to donate, as they are legally allowed to donate other tissue from the age of 16 . The prohibition of the use of stool from persons who are mentally ill in terms of the Mental Health Care Act is supported by the exclusion of stool donors with a personal history of neurological and neurodegenerative disorders, or psychiatric conditions. ${ }^{[6]}$

The regulations on the use of human biological material promulgated in terms of the $\mathrm{NHA}^{[7]}$ do not refer to 'tissue' but use the phrase 'biological material' instead. The latter is defined as 'material from a human being including DNA, RNA, blastomeres, polar bodies, cultured cells, embryos, gametes, progenitor stem cells, small tissue biopsies and growth factors from the same' (emphasis added). Although human stool samples would technically be covered by the scope of both definitions of 'tissue' and 'biological material', the Act refers to the 'removal', 'withdrawal' or 'harvesting' of the tissue (sections 55, 56, 59 and 68), whereas the regulations refer to 'removal' or 'withdrawal' only. Semantically, although the terms 'withdrawal' and 'removal' may not fit the way stool samples are donated and collected for the purpose of FMTs as opposed to the removal of other types of tissue for transplantation, the focus is on the donation of the stool and its subsequent processing or use in FMT. The NHA provides that the 'removal' or 'withdrawal' of human biological material in terms of the regulations may only be performed by a 'competent person', defined as 'trained', and apply to specific health professionals involved in the withdrawal of blood, removal of gametes and fetal tissue, etc. If removed for 'therapeutic purposes', the tissue or biological material may only be 'removed' in an 'authorised', 'prescribed' or 'prescribed research institution' (regulation 2). Applying these legal requirements to FMT would mean that the collection of human stool (e.g. including the donation thereof) should take place in an authorised or prescribed institution. The requirement of the removal of stool by a 'competent person' is clearly redundant. Although donors were allowed to donate stool at home prior to 2018, the US Food and Drug Administration (FDA) now requires the donation to take place on site.

If human stool is considered 'tissue' in terms of the NHA, the storage, testing and processing of the stool for administration (transplantation) should comply with the relevant quality management, safety systems and traceability requirements for tissue banks in terms of the regulations relating to tissue banks, ${ }^{[8]}$ which include standard operating procedures, the keeping of donor records, information on the final destination of tissues, etc.

The clinical administration (transplantation) of the faecal microbiota is very specific, with each route of administration (e.g. enema, colonoscopy, nasogastric) requiring adherence to approved and recognised clinical standards or guidelines. In SA, however, the absence of comprehensive regulations pertaining to tissue transplantation, including organ transplantation, creates significant obstacles for clinicians in the field of tissue and organ transplantation. These practitioners currently have to rely on wholly inadequate provisions in the NHA and existing regulations governing tissue transplantation. The NHA does not define what 'transplantation' is, but the tissue bank regulations describe it as 'the transfer of allograft cells and/or tissue to a recipient', which includes 'musculoskeletal, skin, cardiovascular, and foetal cells and/or tissue', which would cover FMT.

Should one accept that the use of human stool samples as part of FMT is covered by chapter 8 of the NHA as 'tissue' and 'biological material' in terms of the regulations, this would mean that the collection of the stool samples for 'therapeutic purposes' (such as a transplant) would need to comply with the above requirements.
This necessitates a brief explanation of how the collection of stool samples for the purpose of FMT is performed in clinical practice. Based on the US FDA recommendations and the experience of a large US stool bank, it may include on-site stool donation and laboratory processing of material within a specified timeframe, usually within 2 hours after passage. ${ }^{[9]}$

The person who intends to donate a stool sample must undergo a medical examination and submit to blood and stool tests. Prior to this, the potential donor will also need to complete a lengthy questionnaire, similar to blood donation questionnaires, aimed at identifying infectious disease risk factors associated with the microbiome. Donors are excluded for many reasons throughout the four stages of eligibility (online prescreening survey, clinical assessment, stool and nasal screening and blood tests). ${ }^{[10]}$ Examples of reasons for exclusion as a donor include a history of exposure to systemic antibiotics in the past 6 months; being immunocompromised; tattooing or body piercing in the past 6 months, owing to increased infection risk; history of drug use or high-risk sexual behaviour; a history of incarceration; travel to areas with a high risk of endemic infectious disease; a history of chronic gastrointestinal disorders; and a history of autoimmune disease or malignancy. ${ }^{[10]}$ Current studies highlight considerable variability in donor eligibility rates, ranging from $2 \%$ to $32 \%$, despite the use of similar screening programmes. ${ }^{[6]}$ Notably, Kassam et al. ${ }^{[10]}$ recently published the largest screening cohort to date, in which of 15317 consecutive donor candidates, only 386 (3\%) were found to be eligible after the screening process. This report highlights the rigorous screening required to ethicolegally govern FMT repositories.

An FMT is most commonly delivered by colonoscopy, or less frequently by a nasoduodenal tube. Colonoscopic delivery enables administration of a larger dose of material and is associated with the highest efficacy rate in CDI compared with nasoduodenal or enema delivery. ${ }^{[9]}$ During the colonoscopic FMT delivery, the colonoscope is advanced through the entire colon. The material is instilled into the caecum or terminal ileum and allowed to coat the entire length of the large bowel through normal peristalsis. ${ }^{[9]}$

The transplantation of faecal material, also assuming that its collection is governed by chapter 8 of the NHA, requires that removal of the material, as well as the transplant thereof into a recipient, may only be for research or therapeutic purposes (section 64), and must be performed by a medical practitioner only (section 59), in a hospital or authorised institution (section 58(1)(a)), with written authority of the hospital or the medical practitioner in charge of clinical services of that hospital (section 58(1)(b)). The medical practitioner who provides information for consent may not be part of the transplant team (section 58(2)). In addition, section 60 of the NHA stipulates that it is an offence to receive payment for a donation, except 'for the reimbursement of reasonable costs incurred by him or her to provide such donation'.

Considering the novelty of FMTs, should the transplant be considered experimental therapy, section 11 of the NHA requires the health establishment to inform the recipient of a stool transplant in the prescribed manner that the procedure is for experimental or research purposes or part of an experimental or research project and that the patient, his or her treating doctor, the head of the hospital and the relevant research ethics committee have provided prior written consent for such procedure. Chapter 9 of the NHA and the regulations relating to research with human participants ${ }^{[11]}$ provide the requirements that a researcher must comply with in order to conduct research involving human participants. Regulation 2 of these regulations states that research involving human participants must at a minimum comply with the 2015 National Department of 
Health $(\mathrm{NDoH})$ Ethics in Health Research guidelines for unproven interventions in clinical practice. ${ }^{[12]}$ By incorporating the NDoH's ethical guidelines into the research regulations, the ethical guidelines have the force of law and are hence legally binding. The protection of research participants in instances where research is conducted on human tissue is governed by regulation 17 of the regulations relating to tissue banks. ${ }^{[8]}$

Scientific experimentation and clinical trials, be they therapeutic or non-therapeutic, or beneficial to the patient or beneficial to others, are legally permissible provided they conform to the fundamental principles of informed consent to treatment and of emergency treatment, and to the duty of reasonable care, with considerations of public policy in the circumstances. Should an action for damages or a criminal charge flowing from harm allegedly suffered in consequence of improper or unacceptable experimentation arise, courts will be guided by the relevant ethical guidelines, such as the NDoH 2015 Ethics in Health Research guidelines, ${ }^{[12]}$ the guidelines on ethics for medical research of the South African Medical Research Council ${ }^{13]}$ and the NDoH's Guidelines for Good Practice in the Conduct of Clinical Trials (2006), ${ }^{[14]}$ as well as generally acknowledged international codes and declarations on human experimentation and a wide range of international declarations on human rights in general.

\section{Human stool banks as tissue banks}

Currently human stool from patient-selected donors is used predominantly for clinical cases of FMT in SA. Should the treatment become more common, greater access to safe stool will be required. If, as argued above, it is assumed that human stool is tissue to fall within the ambit of the NHA, stool banks will be considered tissue banks. Tissue banks are regulated by the regulations relating to tissue banks in terms of the NHA. ${ }^{[8]}$ The most important stipulations in these regulations are that a tissue bank needs to be authorised by the $\mathrm{NDoH}$ in order to 'remove, acquire or import human tissue from any living or deceased person' (regulation 2(1)(a)). A tissue bank must have a donor record management system in which the donor information is recorded, and the donor's particulars are codified to protect anonymity. There should also be a quality management system in place to trace the donor stool from the recipient back to the original donor (regulation 6). Data necessary to ensure traceability should be kept for a period of 30 years after the donation (regulation 14). The regulations also prescribe that there need to be standard operating procedures in place concerning the quarantine time, processing, storage, labelling and packaging of products (regulations 9 - 16).

Stool banks (tissue banks) should comply with all the requirements stipulated in the regulations. There should also be a freezer in place to store the donations below $80^{\circ} \mathrm{C}$ and a sterilised separate room for the processing of the stools as requested by transplant practitioners. Stool banks should not be situated in close proximity to other tissue banks, as human stool contains many bacteria that should be separated completely from other human tissue, such as tendons and bones at a tissue bank.

\section{Conclusions}

In this article, we have argued that human stool fits the legal framework to be regarded as human tissue, despite the NHA's lack of specificity on the status of human stool as tissue. Human stool donations are currently not addressed in any of the regulations in terms of the NHA, or in the Act itself. A new regulatory framework, such as regulations specifically dedicated to the use of human stool, is the ideal, but may take time to be effected.
In the meantime, and pending any further legal development regarding the use of stool, we argue that stool should be treated as tissue and therefore falls within the regulatory framework of current regulations regulating human tissue, including tissue banks. The classification of other types of human biological material for therapeutic purposes will soon be required. For example, vaginal microbiota transplantation (VMT) is a new treatment option for patients suffering from symptomatic, intractable and recurrent bacterial vaginosis. ${ }^{[15]}$ Although outside of the focus of this article, VMT as a microbiome-based therapy will raise similar, though slightly different, considerations to FMT.

As stated above, faecal microbiota samples may also be processed into capsule form, to be orally administered. The legal framework for processed stool in the form of products requires further consideration, as the requirements, depending on the nature of the end product, may differ from those governing the administration of stool via colonoscopy or nasoduodenal tube discussed in this article. The legal position of a 'faecal microbiota' capsule or other more than minimally manipulated stool products will be highlighted in the third article in the series on the legal regulation of faecal microbiota transplants.

\section{Declaration. None.}

\section{Acknowledgements. None.}

Author contributions. Equal co-authors.

Conflicts of interest. SB is employed by Finch Therapeutics, Somerville, Mass., USA, a company developing microbial therapies related to the treatments described in these articles.

1. Allegretti JR, Mullish BH, Kelly C, Fischer M. The evolution of the use of faecal microbiot transplantation and emerging therapeutic indications. Lancet 2019;394(10196):420-431. https://doi. org/10.1016/S0140-6736(19)31266-8

2. Kao D, Roach B, Silva M, et al. Effect of oral capsule- vs colonoscopy-delivered fecal microbiota transplantation on recurrent Clostridium difficile infection. JAMA 2017;318(20):1985-1993. https:// doi.org/10.1001/jama.2017.17077

3. Jiang ZD, Ajami NJ, Petrosino JF, et al. Randomised clinical trial: Faecal microbiota transplantation for recurrent Clostridum difficile infection - fresh, or frozen, or lyophilised microbiota from a small poo of healthy donors delivered by colonoscopy. Aliment Pharmacol Ther 2017;45(7):899-908. https://doi. org/10.1111/apt.13969

4. Staley C, Hamilton MI, Vaughn BP, et al. Successful resolution of recurrent Clostridium difficile infection using freeze-dried, encapsulated fecal microbiota: Pragmatic cohort study. Am I Gastroenterol 2017;112(6):940-947. https://doi.org/10.1038/ajg.2017.6 5. Allegretti JR, Fischer M, Sagi SV, et al. Fecal microbiota transplantation capsules with targeted colonic
versus gastric delivery in recurrent Clostridium difficile infection: A comparative cohort analysis of versus gastric delivery in recurrent Clostridium difficile infection: A comparative cohort analysis

high and lose dose. Dig Dis Sci 2019;64(6):1672-1678. https://doi.org/10.1007/s10620-018-5396-6

6. Cammarota G, Ianiro G, Kelly CR, et al. International consensus conference on stool banking for faecal microbiota transplantation in clinical practice. Gut 2019;68(12):2111-2121. https://doi.org/10.1136/ gutjnl-2019-319548

7. National Department of Health, South Africa. National Health Act 61 of 2003. Regulations relating to the use of human biological material. Government Gazette 35099, 2 March 2012. (Published under Government Notice R177.) https://www.gov.za/sites/default/files/gcis_document/201409/35099rg969 9gon 177.pdf (accessed 6 July 2020).

8. South Africa. National Health Act 61 of 2003. Regulations relating to tissue banks. Government Gazette No. 35099, 2 March 2012. (Published under Government Notice R182.) https://www.satiba org.za/documents/resources/r182-02-03-2012-tissue-banks.pdf (accessed 25 June 2020).

9. Allegretti JR, Kassam Z, Osman M, Budree S, Fischer M, Kelly CR. The 5D framework: A clinical primer for fecal microbiota transplantation to treat Clostridium difficile infection. Gastrointest Endosc 2017;87(1):18-29. https://doi.org/10.1016/j.gie.2017.05.036

10. Kassam M, Dubois N, Ramakrishna B, et al. Donor screening for faecal microbiota transplantation Kassam M, Dubois N, Ramakrishna B, et al. Donor screening for faecal mi
N Engl J Med 2019;381:2070-2072. https://doi.org/10.1056/NEJMc1913670

11. South Africa. National Health Act 61 of 2003. Regulations relating to research with human participants. Government Gazette 38000, 19 September 2014. (Published under Government Notice R719.) https://www.gov.za/documents/national-health-act-regulations-research-human-participants (accessed 25 June 2020).

12. National Department of Health, South Africa. Ethics in Health Research: Principles, Processes and Structures. Pretoria: NDoH, 2015. http://nhrec.health.gov.za/index.php/grids-preview (accessed 29 October 2019).

13. South African Medical Research Council. The South African Medical Research Council Guidelines on the Responsible Conduct of Research. https://www.samrc.ac.za/research/ethics/guideline-documents (accessed 25 June 2020).

14. National Department of Health, South Africa. Guidelines for Good Practice in the Conduct of Clinical Trials with Human Participants in South Africa. Pretoria: NDoH, 2006. http://www.kznhealth.gov.za/ research/guideline2.pdf (accessed 25 June 2020).

15. Lev-Sagie A, Goldman-Wohl D, Cohen Y, et al. Vaginal microbiome transplantation in women with Lev-Sagie A, Goldman-Wohl D, Cohen Y, et al. Vaginal microbiome transplantation in women with
intractable bacterial vaginosis. Nature Med 2019;25:1500-1504. https://doi.org/10.1038/s41591-019-0600-6 